\title{
AS NECESSIDADES E DESEJOS DE FORMAÇÃO CONTÍNUA DOS PROFESSORES DE PORTUGUÊS LÍNGUA NÃO MATERNA
}

\section{Continuing education needs for teachers of Non-Native Portuguese Language}

\author{
Sandra Valente - Instituto de Educação - Universidade de Lisboa/Portugal
}

\begin{abstract}
RESUMO: Este estudo surgiu da necessidade e desejos de formação que os professores, sobretudo os que lecionam o Português Língua Não Materna. Para que compreendêssemos melhor este fenómeno, a nossa investigação dividiu-se em duas etapas. Em primeiro lugar, realizámos um estudo exploratório numa escola da área metropolitana de Lisboa caracterizada por ter um grande número de alunos provenientes de outras culturas, nomeadamente a africana. e a qual apelidamos de Escola da Praia. Após esta etapa, realizámos um estudo caso numa outra escola da área metropolitana de Lisboa, a Escola do Campo. Esta comunidade caracteriza-se por ser de cariz mais rural e tinha na sua população escolar alunos oriundos do Oeste Asiático. Como metodologia e a par das entrevistas realizadas a membros da direção da escola, às docentes e aos alunos que frequentavam o Português Língua Não Materna, estivemos presentes nas aulas a observar o seu decurso, as interações entre as professoras e os alunos e a prática pedagógica. Foi-nos referido ao longo da nossa intervenção que era fundamental mais formação contínua para que a integração dos alunos estrangeiros se fizesse com maior sucesso e os professores dissipassem as suas fragilidades. Quanto à participação dos alunos, todos referiram a importância que o Português Língua Não Materna teve na progressão das suas aprendizagens, na aquisição do português e na integração social na comunidade educativa.
\end{abstract}

Palavras-chave: Formação de Professores. Interculturalidade. Português Língua não Materna. Necessidade de Formação.

ABSTRACT: This study arose from the need and the desires of training that the teachers, especially those who teach non-native Portuguese. For us to better understand this phenomena, our investigation has been divided into two stages. Firstly, we conducted an exploratory study at a school in Lisbon's metropolitan area characterized by having a large number of students from other cultures, in particular the African culture and what we call Escola da Praia. After this stage, we carried a case study at another school in Lisbon's metropolitan area, Escola do Campo. This community is characterized by being more rural and had in its school population students from West Asia. As a methodology, and alongside the interviews done to members of the school board, teachers and the students that were attending Non-native Portuguese classes, we were present in the classrooms observing the interactions between teachers and the students, and the pedagogical practice. It was referred to us, throughout our intervention, that it was crucial more ongoing training in this context in order to make the integration of foreign students with greater success, and teachers to dissipate their frailties. Regarding the participation of the students, all mentioned the importance that Non-native Portuguese had in the progression of their learning, in the acquisition of Portuguese and in social integration in the educational community.

Educação, Psicologia e Interfaces, Volume 4, Número 1, p. 36-49, Janeiro/Março, 2020.

ISSN: 2594-5343. DOI: https://doi.org/10.37444/issn-2594-5343.v4i1.223 
As necessidades e desejos de formação contínua dos professores de Português Língua Não Materna

Keywords: Teachers training. Interculturalism. Non-native Portuguese. Need of Training.

\section{INTRODUÇÃO}

Este estudo pretende contribuir para o conhecimento das necessidades e desejos de formação dos professores de Português Língua Não Materna (PLNM), através da interpretação que os próprios e seus alunos fazem das suas práticas e concepções de ensino e de aprendizagem nesta área específica e também da análise dessas práticas, a partir da observação das mesmas.

O objeto de estudo foca-se na análise de necessidades e desejos de formação contínua dos professores que lecionam o Português Língua Não Materna na escola pública. Pretende-se também compreender o modo como são implementadas as orientações legislativas regulamentadoras das ações dos professores e das escolas neste campo.

Os professores precisam de adquirir permanentemente conhecimentos e competências que lhes permitam encontrar estratégias adequadas, tendo em vista o sucesso de cada aluno dentro e fora da sala de aula. É esse "domínio e o exercício correcto e orientado da profissionalidade", a que Estrela (2010, pp.67-68) apelida de profissionalismo. Esse profissionalismo pressupõe o desenvolvimento de valores sociais, que envolvam conjuntamente, a escola, os professores, os alunos e as famílias". Para que a competência dos professores seja acompanhada pelo sucesso dos para que todos colaborem "na procura de soluções para os males que afligem a sociedade e a escola alunos é necessário que as escolas tenham recursos suficientes e adequados para os alunos. A escola, enquanto organização, terá de possibilitar a aprendizagem dos professores e, por conseguinte, a dos alunos (BOLÍVAR; BOLÍVAR, 2013).

Com o conhecimento público dos resultados dos estudos Programme for International Student Assessment (PISA) em 2001, e Progress in International Reading Literacy Study (PIRLS), os quais indicavam que o sucesso das minorias estava muito aquém do esperado, começaram a surgir por toda a Europa projetos que visavam melhorar a integração e o aproveitamento dos alunos imigrantes. Exemplos desses projetos foram

Educação, Psicologia e Interfaces, Volume 4, Número 1, p. 36-49, Janeiro/Março, 2020.

ISSN: 2594-5343. DOI: https://doi.org/10.37444/issn-2594-5343.v4i1.223 
a oferta de aulas adicionais da língua de acolhimento ou o início de cursos fora do período letivo, inicialmente para adultos (DUARTE; MOREIRA; FLORES, 2013).

Segundo Duarte et al. (2013), estas medidas não foram totalmente eficazes, pois a aquisição/aprendizagem da L2 fora diminuta. Como justificação referiram as diferenças culturais e linguísticas. Mais tarde, foram realizados estudos comparativistas nos quais foram estudadas e relacionadas as atitudes sociais com a adoção de atitudes políticas em relação ao multilinguismo. Destes estudos, concluiu-se que alguns dos países de imigração (como a Austrália e o Canadá) são capazes de garantir igualdade educativa a minorias étnicas, visto que os resultados dos alunos de culturas minoritárias não foram díspares em relação aos alunos do país de acolhimento. Foram ainda estudadas as organizações educativas. Apurou-se neste caso que, muitas vezes, é nas organizações educativas onde acontece as maiores discriminações.

\section{APRESENTAÇÃO DA PROBLEMÁTICA}

O atual projeto de investigação surge na sequência do estudo apresentado na dissertação de mestrado, cujo foco foi a aprendizagem do Português Língua Não Materna em ambiente de colaboração entre alunos, recorrendo a processos de tutoria por parte dos alunos num ambiente menos formal de aprendizagem que a turma, um clube, e com isso, estudar a sua integração numa escola pública portuguesa. Deste estudo depreendeu-se também que os professores destes alunos não possuíam qualquer formação específica para lidar com esta situação, o que os tornava inseguros. Apesar da formação de base, os professores de português também sentem insegurança, quando trabalham com alunos não falantes da língua portuguesa, pois a formação inicial não os prepara suficientemente e a formação contínua ainda é escassa face ao número crescente de necessidades. Com o projeto atual, pretende-se também conhecer as práticas pedagógicas e didáticas utilizadas pelos professores de Português língua não materna à luz do documento orientador Português língua não materna no currículo nacional (DGIDC, 2005) e compreender como essas práticas se enquadram nos princípios e nas dinâmicas promotoras de uma educação intercultural.

Das mudanças ocorridas nos sistemas educativos e as exigências que se colocam à educação nas sociedades democráticas decorrem necessidades de formação dos 
As necessidades e desejos de formação contínua dos professores de Português Língua Não Materna

professores cujo propósito é orientar a sua preparação para fazer face aos desafios que a realidade cultural das escolas atuais lhes coloca.

O professor tem hoje em dia nas turmas que lhe são confiadas uma forte diversidade cultural e para ensinar os seus alunos precisa antes de mais de (re)conhecer a sua singularidade. Dando o exemplo das nossas escolas, o professor de Língua Não Materna tem nas suas turmas alunos de diferentes origens (chineses, ucranianos, indianos, africanos, ou afrodescendentes, entre outros), cada um tem o seu grupo de pertença, com raízes e identidades culturais diferenciadas, modos de aprendizagem e níveis de proficiência linguística diferentes e até com expetativas escolares variadas.

Esta diversidade requer diferenciação pedagógica. É de salientar que esta questão é transversal a todo o ensino, a todos os níveis e disciplinas, pois a língua portuguesa é a língua de ensino.

A diversidade cultural, na formação inicial, tem sido apenas abordada de forma muito superficial. Estudos, como o de Sequeira (2010) em que o enfoque é a abordagem à diversidade nos curricula de formação inicial de professores do $1 .^{\circ}$ ciclo do Ensino Básico em Portugal, mostram o interesse em desenvolver investigação nesta área.

Este projeto pretende, então, estudar a temática do Português Língua Não Materna, com especial ênfase no estudo das necessidades de formação dos professores que lecionam esta disciplina. Este trabalho terá, também, como fio condutor o contexto em que as escolas estudadas se encontram pois o Português Língua Não Materna é lecionado em escolas com públicos multiculturais. Portanto pretendemos abordar as questões relacionadas com a diversidade cultural no meio escolar, os modos de organização desta oferta educativa nos diferentes contextos institucionais e ainda compreender como se articulam estas práticas organizacionais e as pedagógico-didáticas com as orientações da tutela, as quais envolvem o professor, a sua prática e o desenvolvimento pedagógico.

Partimos, portanto, de duas grandes interrogações que acompanham a construção deste projeto:

1. Que necessidades e desejos de formação contínua manifestam os professores que lecionam o Português Língua Não Materna?

Educação, Psicologia e Interfaces, Volume 4, Número 1, p. 36-49, Janeiro/Março, 2020.

ISSN: 2594-5343. DOI: https://doi.org/10.37444/issn-2594-5343.v4i1.223 
2. Que relações se evidenciam entre as concepções dos professores acerca do ensino e da aprendizagem do PLNM e as necessidades e os desejos de formação que reconhecem para a melhoria do seu desempenho?

\section{A MULTICULTURALIDADE NA EDUCAÇÃO}

Hoje em dia, as exigências feitas à escola são cada vez maiores. A competição sobrepõe-se, muitas vezes, ao espírito colaborativo. A harmonia e a confraternização entre culturas e a disponibilidade dos professores para se dedicarem ao ensino dos novos alunos é muitas vezes negligenciada. Também a coabitação entre várias culturas com diferentes expetativas em relação ao sucesso escolar, é cada vez maior. Assim, o modo como os pais ou educadores, ainda muito enraizados na sua cultura, veem a escola tem uma importância extrema no modo como os alunos encaram o papel da escola e da língua da cultura dominante (BANKS, 2007).

É esse aspeto multicultural que poderá tornar as nossas escolas mais ricas interculturalmente. Entenda-se o primeiro conceito por "the multiplicity of differents cultures which live on the same territory and/ or one taught in the same institution, for example in school or higher education." (ALLEMANN-GHIONDA apud BANKS, 2009, p. 135). A interculturalidade, e segundo a mesma autora, é um conceito mais utilizado no mundo anglo-saxónico, francófono e latino-americano, que integra dimensões sociais, como a interação e convivência entre culturas.

Gay (2000) refere que a perspetiva multicultural não se esgota no tratamento diferenciado dentro do mesmo grupo, mas preocupa-se em encontrar o que está de comum entre todos os membros do grupo. A educação multicultural desenvolveu-se, em parte, para responder às preocupações dos grupos minoritários, pois sentiam-se marginalizados nos países de acolhimento (BANKS; BANKS, 2004; BANKS, 2007).

Num mundo globalizante, os professores, como agentes educativos, precisam de estar conscientes do seu papel na criação de condições para a integração destes na cultura maioritária, para isso é de extrema importância que o professor adote uma postura aberta em relação à educação multicultural e fomentá-la, introduzindo aspetos das culturas dos alunos estrangeiros na sala de aula. No entanto, ainda há professores e alunos que demonstram uma atitude negativa e nacionalista em relação aos originários de outras nações, podendo ser visível em sala de aula (BANKS, 2007). 
As necessidades e desejos de formação contínua dos professores de Português Língua Não Materna

Reforçamos a ideia de que o professor que queira implementar com sucesso uma pedagogia justa, uma pedagogia intercultural, tem de trazer consigo vastos conhecimentos de base, como experiências pessoais, multiculturais e valores pessoais muito fortes, tal como já foi referido por Banks (2007, p. 99): “The skills, knowledge and attitudes necessary to successfully implemente equity pedagogy are the result of study, pratical experience, and reflective self- analysis."

Também Gay (2000) é de opinião que para que se desenvolva uma verdadeira atitude multicultural escolar é necessário que os professores estejam em permanente formação. Esta deverá incluir a aquisição de informação sobre características culturais, princípios pedagógicos, métodos e material adequado para a diversidade cultural, étnica e linguística. Esse conhecimento só surtirá efeito se for aliado à prática e experiência do professor. Esta autora salienta a necessidade de supervisão do trabalho do professor, não só no quadro da formação inicial, como na criação de infraestruturas para apoiar os professores face a esta nova realidade.

Segundo Banks (2007) ensinar é um encontro multicultural que tanto os professores como os estudantes provêm de grupos diversos com diferentes características, tais como: a idade, o grupo social, a etnia, o género. Portanto, estamos perante interações multiculturais involuntárias na sala de aula que poderão ser mais significativas se o professor estiver preparado para responder com sentido de justiça social, usando estratégias diversificadas para ir ao encontro de cada aluno, colocando-o no centro da aprendizagem e não ignorando a sua herança cultural. Esta ideia é também defendida por Porcher (2004, p. 95), que acrescenta que "pour qu'un apprentissage ait lieu, il est indispensable que l'enseignant tienne compte de l'apprenant."

Assim, todos enriquecerão e o clima de escola positivo favorecerá o sucesso e criará uma sociedade mais humana e cuidadora.

\subsection{A multiculturalidade em Portugal}

Em Portugal, o fenómeno da emigração não é novo. Na nossa história houve momentos em que fomos um país de emigrantes. No entanto, a partir do início da década de 90 do século passado passamos a ser também um país de movimentos imigratórios. Esta é uma característica da conjuntura atual, a que rapidamente tivemos de nos adaptar.

Educação, Psicologia e Interfaces, Volume 4, Número 1, p. 36-49, Janeiro/Março, 2020.

ISSN: 2594-5343. DOI: https://doi.org/10.37444/issn-2594-5343.v4i1.223 
Contudo, o estudo de uma língua não urge tão velozmente como estes movimentos. Por tal, os Estados têm a necessidade de criar estratégias/ dispositivos para novos desafios como criar a unidade dentro da diversidade.

Como já foi anteriormente referido, o crescimento súbito da imigração e da mobilidade mundial trouxe consigo mudanças na sociedade, tornando-as multilingues.Com esta nova realidade, a tutela emitiu legislação que regulamentasse o apoio às minorias étnicas presentes na escola e que estas se adaptassem a todas as crianças independentemente da sua condição social, cultural, linguística, entre outras necessidades, tal como já a Declaração de Salamanca, em 1994, o tinha feito.

A legislação que serve de base e guia para o ensino, regula também a igualdade de oportunidades no acesso à escolarização para todos os alunos, nomeadamente os que pertencem a minorias. Então, o país de acolhimento deverá estar preparado para esta nova vaga. A aquisição/aprendizagem da língua é fulcral para o sucesso destes alunos tornando-os competentes no seu uso, pois aqueles que tenham "uma competência insuficiente da língua, da literacia e da instrução têm menor probabilidade de aprender com o mesmo sucesso académico daqueles que são proficientes e/ou falantes nativos" (BIZARRO, 2013, p.17).

Não podemos esquecer também, as funções sociais a ela associadas, já que a língua oficial do país de acolhimento é fundamental para a integração, para a promoção do sucesso e mais uma vez para as oportunidades de aprendizagem. É neste contexto que:
A formação de professores e o seu desenvolvimento pessoal, para além da sua capacitação técnica, deve incluir o desenvolvimento de saberes e capacidades de natureza intercultural e crítica (...). Assim se encoraja os professores a tornarem-se agentes de mudança educativa e de promoção da justiça social (BIZARRO, 2013, p.17).

Os professores têm um papel importantíssimo no desenvolvimento do potencial humano e na formação social do aluno enquanto individuo, sendo através de estratégias e metodologias adequadas que os docentes poderão promover o diálogo intercultural.

Este aspeto é reforçado por Bizarro (2013, p.18) que defende que a preparação dos professores sobre "processos de aquisição/aprendizagem linguística, usos e funções sociais da língua", deve articular-se com a compreensão da diversidade cultural, o que deve ser extensivo a todos os professores. 
As necessidades e desejos de formação contínua dos professores de Português Língua Não Materna

\section{FORMAÇÃO DE PROFESSORES E FORMAÇÃO CONTÍNUA}

Neste campo surgem várias investigações recentes (BIRRELL, 1993; PRAINE, 1989 apud ZEICHNER; HOEFT, 1996; HOLLINS; GUZMAN, 2005) que identificaram vários problemas existentes no ambiente escolar, entre os quais se salienta: falta de informação sobre as culturas dos alunos; na formação inicial, os alunos, futuros professores, não são sensibilizados para o tema; há uma notória falta de preparação dos professores e esse aspeto reflete-se no desempenho em sala de aula; o tema da diversidade cultural é marginalizado, ou seja, ainda não se dá a devida atenção e importância a este assunto.

Segundo Garcia (1999), o conceito de formação é complexo e diverso, pois não apresenta consenso. Contudo, a formação está relacionada com a capacidade e vontade de formação de cada sujeito, o mesmo é dizer que enquanto formando, o sujeito é responsável pelas escolhas, pertinência e o desenvolvimento da formação, tendo em vista o seu aperfeiçoamento profissional para melhorar a qualidade da educação que os alunos recebem

Chantraine-Demailly (1992, p.142) define formação como "os modos de socialização comportando uma função consciente de transmissão de saberes e de saber fazer”. Para esta autora a formação poder-se-á dividir em duas categorias: as formais e as informais. A formal comporta a aprendizagem realizada fora do ambiente do trabalho diário, com caráter mais académico, enquanto a informal acontece, por exemplo, todos os dias, através de conversas com os colegas ou por imitação das observações realizadas.

É sabido que as formações estão enquadradas em modelos e pressupostos teóricos consoante os objetivos a atingir. Contudo, a formação dos professores através de processos de reflexão e de colaboração entre pares tem sido muito valorizada por autores muito diversos (COCHRAN - SMITH; ZEICHNER, 2005; NÓVOA, 1991).

Neste fio condutor, defende-se uma formação que interligue as necessidades do professor como indivíduo e as da escola como instituição, “onde os espaços e tempos de formação estejam ligados aos espaços e tempos de trabalho, em que os lugares de ação possam ser lugares de aprendizagem.” (BOLÍVAR; BOLÍVAR, 2013, p.106).

Segundo Rodrigues e Esteves (1993, pp. 44-45) a formação contínua:

Educação, Psicologia e Interfaces, Volume 4, Número 1, p. 36-49, Janeiro/Março, 2020.

ISSN: 2594-5343. DOI: https://doi.org/10.37444/issn-2594-5343.v4i1.223 
[...] Será aquela que tem lugar ao longo da carreira profissional após a aquisição da certificação profissional inicial (a qual só tem lugar após a conclusão da formação em serviço) privilegiando a ideia de que a sua inserção na carreira docente é qualitativamente diferenciada em relação à formação inicial, independentemente do momento e do tempo de serviço docente que o professor já possui quando faz a sua profissionalização, a qual consideramos ainda como uma etapa de formação inicial.

E como avaliar a formação de professores? É a contribuição para a melhoria da aprendizagem dos professores e consequentemente a dos alunos que falamos quando estamos perante a avaliação da formação de professores (COCHRAN - SMITH; ZEICHNER, 2005). A formação de professores é também importante para gerar processos de transformação das instituições escolares, tornando a aprendizagem uma estratégia para alcançar o sucesso educativo.

\title{
4.1 Análise das necessidades de formação
}

É importante que a formação contínua seja útil e atualizada. Para Tom e Valli (1990, apud RODRIGUES, 1999, p. 51):

\begin{abstract}
A formação contínua surge como um meio de ajustamento continuado de actualização e do aprofundamento dos conhecimentos profissionais e das competências exigidas nos vários domínios da acção educativa, superando lacunas da formação inicial, numa tentativa de melhoria da qualidade de ensino e das aprendizagens e também disponibilizando conhecimentos, capacidades e atitudes favoráveis à mudança e facilitadores das deliberações que o professor tem de efectuar situação singular do exercício profissional.
\end{abstract}

Na perspetiva deste projeto, o professor ao defrontar-se com alunos não falantes do Português, terá de encontrar meios para os motivar, ensinar e integrar na turma e consequentemente no meio escolar. Portanto, é de extrema importância que o professor se envolva na sua formação, frequentando ações de formação contínua. Caso contrário, o professor terá grande dificuldade em acompanhar a transformação permanente de que o sistema educativo é alvo. Pretende-se, assim, que a formação contínua contribua para superar as necessidades dos professores e promova o desenvolvimento profissional e pessoal do docente para que este se torne melhor profissionalmente, logo mais competente. Segundo Zeichner (1993, p. 21): "Discutindo publicamente no seio de grupo de professores, estes têm mais hipótese de aprender uns com os outros e de terem mais uma palavra a dizer sobre o desenvolvimento da sua profissão".

Educação, Psicologia e Interfaces, Volume 4, Número 1, p. 36-49, Janeiro/Março, 2020.

ISSN: 2594-5343. DOI: https://doi.org/10.37444/issn-2594-5343.v4i1.223 
As necessidades e desejos de formação contínua dos professores de Português Língua Não Materna

Para que tal aconteça, deseja-se que haja uma análise de necessidades de formação dos professores. Ela é também necessária no que respeita ao aperfeiçoamento e à transformação de sistemas ou situações. Esta tendência individualista leva a que seja menos provável que os professores consigam confrontar e transformar os aspetos estruturais do seu trabalho que estavam na realização da sua missão educativa.

À medida que a carreira profissional vai avançando, o professor sente a necessidade de ir reciclando o seu conhecimento, pois toma consciência das suas dificuldades, lacunas e desejos. A análise de necessidades tem de fornecer informação sobre lacunas que subsistam nas pessoas, grupos ou instituições em contextos específicos. A análise de necessidades é acima de tudo um instrumento de diagnóstico e uma estratégia de planificação. Queremos que após a análise de necessidades, seguida de formação adequada, haja modificações na melhoria das condições e conhecimentos dos indivíduos. Ao abordar a questão da necessidade falamos em fenómenos como a carência, o interesse, o desejo, a exigência que o individuo sente.

Para Rodrigues (1999, p. 13) as necessidades “[...] produzem-se num complexo processo de negociação, entre a tomada de consciência crítica das exigências sociais e institucionais e a interpelação ética, política e pedagógica das situações singulares do quotidiano a que se tem de fazer frente [...]".

\section{METODOLOGIA}

Pretendemos realizar uma investigação que se enquadra no paradigma fenomenológico -interpretativo. Utilizámos uma metodologia que permitiu recolher informações sobre as necessidades e desejos de formação contínua dos professores de Português Língua Não Materna, com base nas perspetivas dos intervenientes no processo educativo.

Seguimos uma investigação de carácter qualitativo, pois é nossa intenção compreender os "fenómenos educativos a partir da indução dos significados particulares e complexos de cada contexto" (ARAÚJO, 2008, p. 138). Este estudo focou-se em dois Agrupamento de Escolas e estudou as suas dinâmicas, os professores e as suas práticas à luz da legislação preconizada para PLNM.

Educação, Psicologia e Interfaces, Volume 4, Número 1, p. 36-49, Janeiro/Março, 2020.

ISSN: 2594-5343. DOI: https://doi.org/10.37444/issn-2594-5343.v4i1.223 
Para dar resposta ao problema que nos propusemos investigar, pensámos que a conjugação de recolha de dados em modos diferentes seria a mais adequada. Foi nossa pretensão fazer a triangulação de métodos (HUSEN; POSTLETHWAITE, 1985) para tornar a nossa investigação mais credível e fiável.

Numa primeira etapa, as entrevistas tiveram como objetivo caracterizar o caso e compreender a evolução que o ensino de PLNM tem vindo a sofrer, naquele contexto, ao longo dos últimos cinco anos. As entrevistas foram realizadas a membros da gestão, por estes terem uma ideia mais abrangente da evolução do ensino, inerente ao cargo que desempenham, nomeadamente em termos legislativos; aos professores que serão o elemento -chave desta investigação. É junto deles que perceberemos a situação em que se encontra a formação, os seus desejos e necessidades. Foi ainda realizada uma entrevista "focus goup" aos alunos de PLNM.

Na segunda etapa, trabalhámos com as professoras de PLNM dos Agrupamentos para inferirmos com maior detalhe as respostas às questões de investigação.

Nesta fase, recorremos à observação naturalista para conhecermos as práticas e dinâmicas utilizadas em contexto de sala de aula. Realizámos também "mini -entrevistas", que segundo A. Estrela (1994, p. 348) "correspondem a trocas informais de opiniões, a realizar (...) imediatamente antes e após as aulas”. Estas mini-entrevistas tiveram como objetivo compreender algum aspeto da aula que se esteve a observar. Com estas técnicas de recolha de dados tentaremos compreender a praxis (COCHRAN SMITH; ZEICHNER, 2005), interação entre a prática e o pensamento destas professoras.

Tendo em vista os desejos de formação deste professore, os resultados desta etapa serão, posteriormente, triangulados com aqueles que se obtiveram na primeira etapa do estudo.

\section{CONSIDERAÇÕES FINAIS}

Este estudo encontra-se em fase de análise de conteúdo pelo que ainda é muito precoce tecer alguma conclusão definitiva. No entanto, ao longo das entrevistas que realizámos, todos os intervenientes focaram a importância do Português Língua Não Materna.

Educação, Psicologia e Interfaces, Volume 4, Número 1, p. 36-49, Janeiro/Março, 2020.

ISSN: 2594-5343. DOI: https://doi.org/10.37444/issn-2594-5343.v4i1.223 
As necessidades e desejos de formação contínua dos professores de Português Língua Não Materna

A docente entrevistada refere que é "essencial para eles (os alunos) conseguirem completar o seu currículo escolar" (entrevistada A). Por seu lado, os alunos referem o gosto por estas aulas "porque aqui podemos falar e somos ouvidos".

É de salientar que o membro da direção também menciona o facto do PLNM contribuir para o sucesso e a integração de todos.

Outro ponto verificado foi a não adequação da legislação na prática da escola, ou seja, segundo uma das entrevistadas apesar de existir legislação nesta área na prática ela não é aplicada, porque a tutela assim não o permite, sendo "uma incoerência total". Acrescenta ainda que "o PLNM devia ser uma disciplina, ponto final" (entrevistada B).

Estamos cientes que ainda há um grande caminho a percorrer, mas se houver troca de experiências e "a ajuda dos colegas" (entrevistada A) o processo de ensinoaprendizagem será facilitado e o sucesso dos alunos estará garantido.

\section{REFERÊNCIAS BIBLIOGRÁFICAS}

ARAÚJO, S. Contributos para uma educação para a cidadania: professores e alunos em contexto intercultural - (Teses; 17). Lisboa: ACIDI, 2008.

BANKS J.; BANKS, C. Handbook of research on Multicultural Education. New York: McMillan, 2004.

BANKS, J. Educating citizens in a multicultural society. New York: Teachers College Press, 2007.

BANKS, J. The Routledge international companion to multicultural education. New York: Routledge, 2009.

BIZARRO, R., MOREIRA M.A. ; FLORES C. Português Língua Não Materna: Ensino e Investigação. Lisboa: Lidel, 2013.

BIZARRO, R.; BRAGA, F. A formação de professores de PLNM na FLUP: questões interculturais e ensino inclusivo do português língua segunda In: BIZARRO, R.; MOREIRA, M.A.; FLORES, C.. Português Língua Não Materna: Ensino e investigação. Lisboa: Lidel, 2013.

BOLÍVAR A.; BOLÍVAR R. Formação de Professores. In: BIZARRO, R.; MOREIRA, M.A.; FLORES, C.. Português Língua Não Materna: Ensino e investigação. Lisboa: Lidel, 2013.

Educação, Psicologia e Interfaces, Volume 4, Número 1, p. 36-49, Janeiro/Março, 2020.

ISSN: 2594-5343. DOI: https://doi.org/10.37444/issn-2594-5343.v4i1.223 
CHANTRAINE - DEMAILLY, L. Modelos de formação contínua e estratégias de mudança. In: NÓVOA, A. (Org.) Os professores e a sua formação. Lisboa:

Publicações D. Quixote - Instituto de Inovação Educacional, 1992.

COCHRAN -SMITH, M.; ZEICHNER, K. Studying Teacher Education: The report of the AERA panel on research and teacher education. American Educational Research Association, 2005.

DGIDC. Documento orientador sobre o português língua não materna no currículo nacional - programa para a integração dos alunos que não têm o português como língua materna. Lisboa: ME/DGIDC, 2005.

DUARTE, J. MOREIRA M.A; FLORES C. Bilinguismo e educação: um novo currículo para a formação de professores. In: BIZARRO, R.; MOREIRA, M.A.; FLORES, C.. Português Língua Não Materna: Ensino e investigação. Lisboa: Lidel, 2013.

ESTEVES, M.; RODRIGUES, A. (orgs.). Análise de Necessidades na Formação de Professores. Colecção Ciências da Educação. Porto: Porto Editora, 1993.

ESTRELA, A. Teoria e Prática de Observação de Classes: Uma estratégia de formação de professores. Porto: Porto Editora (4. ${ }^{a}$ edição), 1994.

ESTRELA. M. T. Profissão docente- dimensões afectivas e éticas. Maia: Areal Editores, 2010.

GARCÍA, C.M. Formação de Professores - Para uma mudança educativa. Porto: Porto Editora, 1999.

GAY, G. Culturally Responsive Teaching - Theory, research \& practice. New York: Teachers College Press, 2000.

HOLLINT. E.; GUZMAN, M. T. Research on Preparing Teachers for Diverse Populations. In: COCHRAN-SMITH, M.; ZEICHNER, K. M. (Org.). Studying Teacher Education, New York: AERA and LEA, 2005.

HUSEN, T.; POSTLETHWAITE, T.N. (org).The International Encyclopedia of Education, vol. V. Oxford: Pergamon Press, 1985.

NÓVOA, A. Concepções e práticas de formação contínua de professores. In: Formação contínua de professores; realidades e prespectivas. Aveiro: Universidade de Aveiro, 1991.

PORCHER, L. L 'enseignement des langues étrangères. Paris: Hachette, 2004.

RODRIGUES, M. A. Metodologias de Análise de Necessidades de Formação na Formação Profissional Contínua de Professores. Universidade de Lisboa, Lisboa, 1999. 
As necessidades e desejos de formação contínua dos professores de Português Língua Não Materna

SEQUEIRA A. Formação inicial de professores do $1^{\circ}$ ciclo do ensino básico: vários olhares sobre a diversidade cultural. Lisboa: Universidade de Lisboa. (Texto Policopiado), 2010.

ZEICHNER, K. A Formação Reflexiva de Professores: Ideias e Práticas. Lisboa: Educa, 1993.

ZEICHNER, K. M.; HOEFT, K. Teacher socialization for cultural diversity. In: SIKULA J.; BUTTERY, T.J.; GUYTON, E. (Eds), Handbook of research on teacher education (2nd ed.), pp. 525-547). New Iork: Macmillan, 1996.

\section{Credenciais da autora}

VALENTE, Sandra.Professora na Fundação Universitária Iberoamericana, graduada em Professores do Ensino Básico, variante de Português-Francês (ESELX-IPL), Mestre Ciências da Educação, especialização em Mediação em Educação (IE-UL). E-mail: sandravalente.pereira@gmail.com

Endereço para correspondência: Sandra Valente. Rua Conselheiro Lopo Vaz, n.46, $7^{\circ}$ dto, 1800-142 Lisboa/Portugal. Email: sandravalente.pereira@gmail.com

Como citar este artigo (Formato ABNT): VALENTE, Sandra. As necessidades e desejos de formação contínua dos professores de Português Língua Não Materna. Educação, Psicologia e Interfaces, v. 4, n. 1, p.36-49, 2020. DOI: https://doi.org/10.37444/issn-2594-5343.v4i1.223

Recebido: 04/10/2019.

Aceito: 20/11/2019.

Educação, Psicologia e Interfaces, Volume 4, Número 1, p. 36-49, Janeiro/Março, 2020.

ISSN: 2594-5343. DOI: https://doi.org/10.37444//issn-2594-5343.v4i1.223 